\title{
CAMBRIDGE
}

\section{General Relativity}

An Einstein Centenary Survey

Edited by S. W. HAWKING and W. ISRAEL

Over the past twenty years unprecedented advances have been made both in observational astronomy and technology and in our theoretical understanding of relativity, enabling Einstein's general theory of relativity to be verified to high precision. On the occasion of Einstein's hundredth birthday twenty-one of the world's leading relativists have collaborated to produce this survey of the current experimental and theoretical status of general relativity and to point the way to future research. This unique book which will remain a standard work for years to come will be invaluable to astronomers and relativists throughout the world.

927 pp. 3 half-tones, 13 tables, 69 line figures

0521222850

$\mathbf{f 3 7 . 5 0 ~ n e t ~}$

\section{Sources of Gravitational Radiation Edited by LARRY L. SMARR}

In this volume, the most active and distinguished researchers in the field present a timely survey of dynamical general relativity with accounts both of the theoretical foundations of dynamical relativity and of current research which is now at a crossroads. This book will be an essential reference source for all those involved in gravitational physics and related fields.

$512 \mathrm{pp}$. numerous tables and line diagrams

$052122778 X$

\section{Active Galactic Nuclei}

\section{Edited by C. HAZARD and S. MITTON}

This book contains a collection of review talks given at a NATO summer school in Cambridge, which summarise the main theoretical ideas that have emerged from the investigation of excited galaxies and quasars. In recent years the study of the nuclei of active galaxies has advanced rapidly and it is thus timely to provide a survey of this exciting area of theoretical research in high-energy astrophysics and extragalactic astronomy. The book, written by leading researchers in the field, will appeal to research workers, post-graduates and keen sky-watchers with an interest in the astronomy of the far-universe.

Cambridge Astrophysics Series

c. 300 pp. 1 half-tone, 13 tables, 52 line diagrams

0521224942

\section{CAMBRIDGE UNIVERSITY PRESS}


Continued from back cover

Soliton formation in magnetoactive Vlasov plasmas

J. G. TURNER AND T. J. M. BOYD

The spectrum of second harmonic emission from a laser-produced plasma

R. A. CAIRNS

The resistive evolution of force-free magnetic fields. Part 2.

Relation to anisotropic diffusion

J. REID AND E. W. LAING

Free expansion of a plasma with two electron temperatures

L. M. WICKENS AND J. E. ALLEN

Convection of a weakly ionized plasma in a strong magnetic field: nonaxisymmetric waves

B. K. SHIVAMOGGI AND M. S. UBEROI 


\section{JOURNAL OF PLASMA PHYSICS}

\section{Volume 22 Part 1 August 1979}

\section{CONTENTS}

Magnetic field line reconnexion by localized enhancement of resistivity. Part 4. Dependence on the magnitude of resistivity M. UGAI AND T. TSUDA

Nonlinear interaction of wave packets

J. T. MENDON CुA

Nonlinear Kelvin-Helmholtz instability in hydromagnetics

H. NAGANO

Hydrodynamical description of one-component weakly coupled plasmas

W. ROZMUS

Instability of ion-ion hybrid waves in current-carrying collisional plasmas with two ion species

K. F. LEE

Lower hybrid oscillating, two-stream instability in a plasma with magnetic shear

J. M. WERSINGER, A. H. KRITZ AND F. TROYON

Electromagnetic wave backscattering across a magnetic field in a bounded plasma

J. E. WILLETT, S. BILIKMEN AND B. MARAGHEOHI

An analytical local approach to flux conserving tokamak equilibrium

J. J. RAMOS

Oscillation centres and mode coupling in nonuniform Vlasov plasma

8. JOHNSTON AND A. N. KAUFMAN

Continued on inside back cover

C. Cambridge University Press 1979

CAMBRIDGE UNIVERSITY PRESS

THE PITT BUILDING, TRUMPINGTON STREET, CAMBRIDGE CB2 1 RP

32 BAST 57TH STREET, NEW YORK, N.Y. 10022

Printed in Great Britain at the University Press, Cambridge 